\title{
Pengaruh Penerapan Keselamatan Dan Kesehatan Kerja (K3) Serta Lingkungan Kerja Terhadap Produktivitas Kerja Di Surabaya
}

\author{
Ahmad Zainul Arifin ${ }^{1}$ dan Feri Harianto ${ }^{2}$ \\ ${ }^{1,2}$ Jurusan Teknik Sipil, Fakultas Teknik Sipil dan Perencanaan,ITATS, Surabaya \\ E-mail: zain.ipin97@gmail.com ${ }^{1}$,gokbio@yahoo.com ${ }^{2}$
}

\begin{abstract}
ABSTRAK: Semua pekerjaan dituntut agar dapat menghasilkan kualitas yang baik dengan waktu yang telah ditentukan. Salah satunya adalah pekerjaan proyek konstruksi yang saat ini mengalami perkembangan pesat di Indonesia dengan memperhatikan produktivitas kerja. Proyek konstruksi tidak lepas dari keselamatan dan kesehatan kerja yang bisa menunjang suatu pekerja bisa menyelesaikan pekerjaan. Serta lingkungan kerja yang mendukung suatu pekerjaan. Keselamatan dan kesehatan kerja serta lingkungan kerja bisa mempengaruhi produktivitas kerja di suatu proyek konstruksi. Teknik pengambilan penelitian menggunakan metode non probability sampling disertai teknik purposive sampling dengan cara penyebara kuesioner. Responden penelitian adalah mandor, tukang dan pekerja kasar. Penyebaran kuesioner di 3 proyek, yaitu proyek pembangunan Rumah Sakit Katolik St Vicentius Paulo (RKZ), proyek pembangunan Apartmen Puncak Merr, dan proyek pembangunan Apartmen Belleview Manyar. Berdasarkan hasil analisis penelitian menyatakan bahwa variabel keselamatan dan kesehatan kerja (X1) berpengaruh signifikan terhadap produktivitas kerja (Y) dengan nilai (T-statistic=14,487 > 1,96) dan $(P$-values $=0,000<0,05)$. Sedangkan untuk variabel lingkungan kerja (X2) berpengaruh signifikan terhadap produktivitas kerja $(\mathrm{Y})$ dengan nilai $(T$-statistic $=3,962$ $>1,96)$ dan $(P$-values $=0,000<0,05)$.
\end{abstract}

Kata Kunci : Keselamatan dan kesehatan kerja, lingkungan kerja, produktivitas kerja.

\section{PENDAHULUAN}

Perkembangan konstruksi saat ini dituntut agar suatu proyek konstruksi dapat menghasilkan kualitas yang baik dengan waktu yang telah ditentukan. Kualitas yang baik akan memerlukan sumber daya yang baik khususnya manusia. Maju mundurnya suatu perusahaan sangat ditunjang oleh tenaga kerja. Oleh karena itu untuk dapat mewujudkan tenaga kerja yang berkualitas, sehat dan produktif diperlukan adanya suatu pengukuran produktivitas pekerja yang bertujuan untuk menghasilkan produktivitas kerja secara optimal sesuai yang direncanakan. Dalam penerapan keselamatan dan kesehatan kerja harus mendapat perhatian yang sungguhsungguh untuk meningkatkan produktivitas kerja. Hal tersebut sesuai dengan penelitian yang dilakukan oleh (Christina dkk, 2012) yang menyatakan bahwa semakin tinggi budaya (kebiasaan) dalam menerapkan Keselamatan dan Kesehatan Kerja (K3), maka semakin tinggi pula tingkat produktivitas kerja yang dihasilkan.

Menurut Meggison dalam Wahyuni (2018) mendefinisikan bahwa keselamatan kerja adalah keselamatan yang berhubungan dengan aktivitas kerja manusia baik pada industri, manufaktur dan kontruksi, yang melibatkan mesin, peralatan, penanganan material, alat kerja bahan baku dan proses pengolahannya, tempat kerja dan lingkungannya serta cara-cara melakukan pekerjaan, maupun industri jasa yang melibatkan peralatan pembersih gedung, sarana transportasi, dan lainlain.

Menurut Siswanto (2015) menyatakan bahwa keselamatan kerja adalah suatu cara untuk melindungi tenaga kerja dari luka yang disebabkan oleh kecelakaan yang berhubungan dengan pekerjaan. Resiko keselamatan dipengaruhi oleh lingkungan yang menyebabkan kebakaran, patah tulah, kesleo, serta kerugian alat tubuh seperti penglihatan dan pendengaran. Sedangkan kesehatan kerja adalah situasi dimana bebas dari gangguan fisik atau rasa sakit yang disebabkan oleh lingkungan kerja. Resiko kesehatan merupakan fakta- fakta dalam lingkungan kerja yang bekerja melebihi waktu yang ditentukan.

Lingkungan kerja adalah suatu tempat dimana para pekerja sedang melakukan aktivitas pekerjaan. Lingkungan kerja yang baik akan mempunyai dampak yang positif kepada pekerjanya. Hal ini didukung dengan adanya penelitian yang dilakukan oleh Hidayat dkk (2014) yang menyatakan bahwa faktor lingkungan kerja memiliki pengaruh yang cukup signifikan terhadap produktivitas tenaga kerja. Menurut Suardi (2010) menyatakan bahwa lingkungan kesehatan tempat kerja yang kurang baik dapat menurunkan derajat kesehatan dan kinerja para pekerja. Oleh karena itu diadakan upaya pengendalian dengan tujuan untuk dapat mencegah dan mengurangi serta dapat menekan agar hal tersebut tidak terjadi. Didalam kesehatan kerja terdapat kesegaran jasmani dan rohani. Semakin tinggi lingkungan kerja, maka akan semakin tinggi kinerja pada proyek konstruksi. Maksudnya yaitu lingkungan kerja yang aman dan sehat akan meningkatkan kualitas kerja para pekerja sehingga produktivitas para pekerja akan meningkat. Sedangkan penelitian yang dilakukan oleh Faris dan Harianto (2014) menyatakan bahwa lingkungan kerja tidak berpengaruh terhadap kecelakaan kerja sehingga kecelakaan kerja akan menghambat produktivitas kerja.

Dalam upaya untuk mengetahui tingkat produktivitas pekerja di lokasi proyek maka perlu dilakukan sebuah penelitian. Berdasarkan uraian diatas maka dilakukan penelitian untuk mengetahui produktivitas tenaga kerja yang dipengaruhi oleh penerapan keselamatan dan kesehatan kerja (K3) serta lingkungan kerja. Rumusan masalah dalam penelitian ini adalah bagaimana pengaruh keselamatan dan kesehatan kerja terhadap produktivitas kerja dan bagaimana pengaruh lingkungan kerja terhadap produktivitas kerja.

\section{METODE PENELITIAN}

Metode yang digunakan adalah metode survei, Teknik pengambilan sampel penelitian ini dilakukan menggunakan metode non probability sampling disertai 
teknik purposive sampling merupakan teknik pengambilan sampel yang sudah direncanakan oleh peniliti. Maksudnya peneliti tidak memilih responden secara acak melainkan berdasarkan tujuan tertentu dari peneliti. Menurut Ghozali (2015) menyatakan bahwa dalam pemakaian software aplikasi Smart PLS direkomendasikan menggunakan sampel antara 30 sampai dengan 100. Sehingga dalam penelitian ini menggunakan 75 sampel. Pengumpulan data menggunakan penyebaran kuesioner. responden yang dipilih mandor,tukang, dan pekerja kasar. Dalam penelitian ini diambil 3 proyek yang mewakili daerah Surabaya serta sudah menerapkan K3.

1. Proyek pertama adalah proyek pembangunan Rumah Sakit Katolik St Vicentius Paulo (RKZ).

2. Proyek kedua adalah proyek pembangunan Apartmen Puncak Merr.

3. Proyek yang ketiga adalah proyek pembangunan Apartmen Belleview Manyar.

Penelitian ini menggunakan kuesioner yang isinya meliputi variabel Keselamatan dan Kesehatan Kerja \{X1), Lingkungan Kerja (X2), Produktivitas Kerja (Y). Dan terdiri dari beberapa indikator yang meliputi Penyediaan Alat Pelindung Diri (X1.1), Kepemimpinan dan Administrasi (X1.2), Peningkatan kesadaran terhadap K3 (X1.3), Hubungan antar tenaga kerja (X2.1), Suasana kerja (X2.2), Fasilitas tenaga kerja (X2.3), Kualitas kerja (Y1.1), Kuantitas kerja (Y1.2), Ketepatan waktu (Y1.3). Lebih lengkap terdapatpada Gambar 1 terkait kerangka model penelitian.

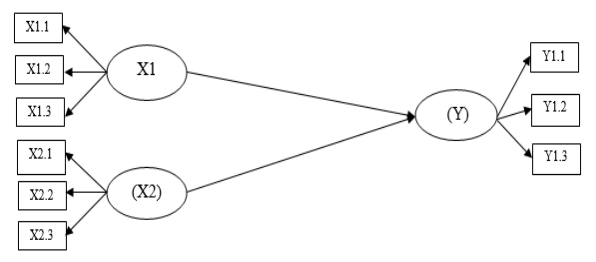

Gambar 1. Kerangka Model Penelitian

\section{HASIL PENELITIAN DAN PEMBAHASAN Frejuensi Penelitian Responden}

Frekuensi penilaian responen untuk pengukuran variabel ini dilakukan dengan penyebaran kuesioner terhadap responden. Penilaian angka yang digunakan untuk pengolahan data merupakan hasil dari pembulatan nilai rata-rata untuk setiap indikator yang memiliki satu atau lebih dari satu pertanyaan, dengan total 3 variabel, 9 indikator dan 30 pertanyaan serta skala pengukuran dari satu sampai dengan lima untuk semua pertanyaan. Tabel 1 menunjukan rekapitulasi penilaian responden terhadap variabel indikator

Dari Tabel 1 akan dilakukan pentabelan ulang untuk menyesuaikan data yang dibutuhkan dengan format csv fungsinya agar data yang didapat bisa dihitung dengan software smart-pls. setelah format penyimpanan data dari excel dirubah menjadi csv maka data tersebut sudah siap untuk diproses dengan menggunakan software smart pls. setelah kita sudah memverifikasi data dalam smart pls maka selanjutnya kita membentuk konstruk dari setiap variabel, Setelah dibentuknya konstruk dari setiap variabel maka tahap selanjutnya dilakukan perhitungan satu persatu dimulai dari sebelum dimoderasi kemudian sesudah dimoderasi dengan tahap calculate ke $p l s$ algoritsm maka akan mengeluarkan hasil dari setiap konstruk yang sudah dibentuk seperti pada Gambar 2 berikut.

Tabel 1 Rekapitulasi Penilaian Responden

\begin{tabular}{|c|c|c|c|c|c|c|c|}
\hline \multirow[t]{2}{*}{ No } & \multirow[t]{2}{*}{ Pertanyaan } & \multicolumn{5}{|c|}{ Jawaban } & \multirow[t]{2}{*}{ Tot } \\
\hline & & 1 & 2 & 3 & 4 & 5 & \\
\hline 1 & $\begin{array}{l}\text { Penyediaan } \\
\text { Alat } \\
\text { Pelindung } \\
\text { Diri (APD) } \\
\text { (X1.1) }\end{array}$ & 0 & 1 & 3 & 55 & 16 & 75 \\
\hline 2 & $\begin{array}{l}\text { Kepemimpina } \\
\mathrm{n} \text { dan } \\
\text { Administrasi } \\
\text { (X1.2) }\end{array}$ & 0 & 10 & 28 & 23 & 14 & 75 \\
\hline 3 & $\begin{array}{l}\text { Peningkatan } \\
\text { kesadaran } \\
\text { terhadap K3 } \\
\text { (X1.3) }\end{array}$ & 0 & 1 & 42 & 23 & 9 & 75 \\
\hline 4 & $\begin{array}{l}\text { Hubungan } \\
\text { antar tenaga } \\
\text { kerja (X2.1) }\end{array}$ & 0 & 1 & 22 & 52 & 0 & 75 \\
\hline 5 & $\begin{array}{l}\text { Suasana kerja } \\
\text { (X2.2) }\end{array}$ & 0 & 2 & 6 & 60 & 2 & 75 \\
\hline 6 & $\begin{array}{l}\text { Fasilitas kerja } \\
\text { tenaga kerja } \\
(\mathrm{X} 2.3)\end{array}$ & 0 & 0 & 0 & 48 & 27 & 75 \\
\hline 7 & $\begin{array}{l}\text { Kualitas kerja } \\
\text { (Y1.1) }\end{array}$ & 0 & 2 & 18 & 42 & 3 & 75 \\
\hline 8 & $\begin{array}{l}\text { Kuantitas } \\
\text { kerja (Y1.2) }\end{array}$ & 0 & 1 & 33 & 28 & 13 & 75 \\
\hline 9 & $\begin{array}{l}\text { Ketepatan } \\
\text { waktu (Y1.3) }\end{array}$ & 0 & 0 & 17 & 20 & 38 & 75 \\
\hline \multicolumn{2}{|c|}{ Total Jawaban } & 0 & 18 & 169 & 351 & 122 & \\
\hline
\end{tabular}

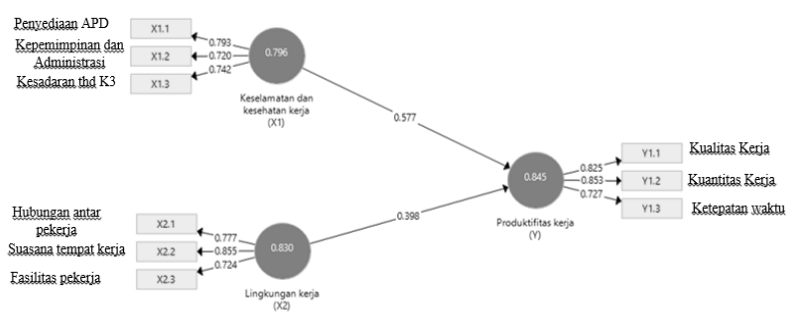

Gambar 2. Konstruk dari setiap variabel

Dari hasil perhitungan smart pls maka didapat hasil seperti Gambar 2, dari hasil tersebut bisa diketahui uji validitas convergent, validitas discriminant dan uji reliabilitas untuk uji permodelan outer model, mengetahui hasil $R$-square, effect size dan uji signifikan untuk uji permodelan inner model. untuk lebih jelas tentang analisis data yang dihasilkan dari uji permodelan maka akan dijelaskan dalam pengertian dibawah ini

\section{Menghitung Pengukuran Outer Model}

\section{a. Uji Validitas Convergent}

Validitas Convergent adalah hasil yang didapat unutk menunjukkan nilai setiap indikator yang mewakili atau 
endasari variabel laten tersebut. berikut adalah hasil dari perhitungan data dengan uji validitas convergent pada Tabel 2 dan 3.

Tabel 2. Nilai Outer Loading

\begin{tabular}{|c|c|c|c|c|}
\hline Variabel & $\mathbf{X 1}$ & $\mathbf{X 2}$ & $\mathbf{Y}$ & Keterangan \\
\hline $\mathbf{X 1 . 1}$ & 0.861 & & & Valid \\
\hline $\mathbf{X 1 . 2}$ & 0.843 & & & Valid \\
\hline $\mathbf{X 1 . 3}$ & 0.714 & & & Valid \\
\hline $\mathbf{X 2 . 1}$ & & 0.867 & & Valid \\
\hline $\mathbf{X 2 . 2}$ & & 0.773 & & Valid \\
\hline $\mathbf{X 2 . 3}$ & & 0.876 & & Valid \\
\hline $\mathbf{Y 1 . 1}$ & & & 0.812 & Valid \\
\hline $\mathbf{Y 1 . 2}$ & & & 0.876 & Valid \\
\hline $\mathbf{Y 1 . 3}$ & & & 0.853 & Valid \\
\hline
\end{tabular}

Tabel 3. Nilai AVE

\begin{tabular}{|l|c|}
\hline \multicolumn{1}{|c|}{ Variabel } & AVE \\
\hline $\begin{array}{l}\text { Keselamatan dan Kesehatan } \\
\text { Kerja }\end{array}$ & 0.654 \\
\hline Lingkungan Kerja & 0.706 \\
\hline Produktifitas Kerja & 0.718 \\
\hline
\end{tabular}

Berdasarkan hasil dari Tabel 2 dan 3 menunjukkan bahwa nilai variabel indikator dengan variabel laten memiliki nilai refleksi tinggi dan mempunyai hasil yang memenuhi syarat perhitungan outer loading nilai harus $>0,70$.

Variabel Keselamatan dan Kesehatan Kerja (X1) diukur dengan 3 indikator yaitu indikator pertama penyediaan Alat Pelindung Diri (APD) (X1.1) dengan hasil 0,861, kedua kepemimpinan dan administrasi (X1.2) dengan hasil 0,843 , ketiga kesadaran terhadap K3 (X1.3) dengan hasil 0,714.

Variabel lingkungan kerja (X2) diukur dengan 3 indikator yaitu indikator pertama hubungan antar pekerja (X2.1) dengan hasil 0,867, kedua adalah indikator suasana tempat kerja (X2.2) dengan hasil 0,773, ketiga adalah indikator fasilitas kerja (X2.3) dengan hasil 0,876.

Variabel produktivitas kerja (Y) diukur dengan 3 indikator yaitu indikator pertama kualitas kerja (Y1.1) dengan hasil 0,812, kedua adalah indikator kuantitas kerja (Y1.2) dengan hasil 0,876, ketiga adalah indikator ketepatan waktu (Y1.3) dengan hasil 0,853.

Dan untuk nilai AVE pada tabel 4.6 didapat hasil dengan keselamatan dan kesehatan kerja (X1) sebesar 0,654, suasana kerja (X2) sebesar 0,706, dan produktivitas kerja (Y) sebesar 0,718. Dari semua nilai yang dihasilkan AVE memenuhi syarat > 0,50 sehingga semua indikator dalam penelitian ini dinyatakan valid.

\section{b. Uji Validitas Discriminant}

Uji Validitas Discriminant merupakan nilai yang didapat digunakan untuk ukuran konstruk dari indikator satu dengan indikator yang lain itu berbeda. Hasil dari perhitungan data dengan uji validitas discriminant dapat dilihat pada Tabel 4,5 dan 6 .

Tabel 4. Latent Variable Correlations

\begin{tabular}{|c|c|c|c|}
\hline & $\begin{array}{c}\text { Keselamatan dan } \\
\text { kesehatan kerja } \\
\text { (X1) }\end{array}$ & $\begin{array}{c}\text { Lingkungan } \\
\text { Kerja (X2) }\end{array}$ & $\begin{array}{c}\text { Produktifitas } \\
\text { Kerja (Y) }\end{array}$ \\
\hline X1 & 0.809 & & \\
\hline X2 & 0.297 & 0.84 & \\
\hline Y & 0.821 & 0.464 & 0.847 \\
\hline
\end{tabular}

Tabel 5. Nilai Akar AVE

\begin{tabular}{|l|c|c|}
\hline \multicolumn{1}{|c|}{ Variabel } & AVE & Akar AVE \\
\hline $\begin{array}{l}\text { Keselamatan dan } \\
\text { Kesehatan Kerja }\end{array}$ & 0.654 & 0.8087027 \\
\hline $\begin{array}{l}\text { Lingkungan } \\
\text { Kerja }\end{array}$ & 0.706 & 0.8402381 \\
\hline $\begin{array}{l}\text { Produktifitas } \\
\text { Kerja }\end{array}$ & 0.718 & 0.8473488 \\
\hline
\end{tabular}

Tabel 6. Nilai Cross Loading

\begin{tabular}{|c|c|c|c|}
\hline Variabel & $\begin{array}{c}\text { Keselamatan } \\
\text { dan } \\
\text { Kesehatan } \\
\text { Kerja (X1) }\end{array}$ & $\begin{array}{c}\text { Lingkungan } \\
\text { Kerja (X2) }\end{array}$ & $\begin{array}{c}\text { Produktifitas } \\
\text { kerja (Y) }\end{array}$ \\
\hline X1.1 & $\mathbf{0 . 8 6 1}$ & 0.430 & 0.683 \\
\hline X1.2 & $\mathbf{0 . 8 4 3}$ & 0.325 & 0.749 \\
\hline $\mathbf{X 1 . 3}$ & $\mathbf{0 . 7 1 4}$ & -0.111 & 0.540 \\
\hline $\mathbf{X 2 . 1}$ & 0.245 & $\mathbf{0 . 8 6 7}$ & 0.444 \\
\hline $\mathbf{X 2 . 2}$ & 0.179 & $\mathbf{0 . 7 7 3}$ & 0.311 \\
\hline $\mathbf{X 2 . 3}$ & 0.314 & $\mathbf{0 . 8 7 6}$ & 0.398 \\
\hline Y1.1 & 0.58 & 0.515 & $\mathbf{0 . 8 1 2}$ \\
\hline Y1.2 & 0.648 & 0.344 & $\mathbf{0 . 8 7 6}$ \\
\hline Y1.3 & 0.828 & 0.338 & $\mathbf{0 . 8 5 3}$ \\
\hline
\end{tabular}

Berdasarkan hasil pada Tabel 45 dan 6 hasil dari cross loading diatas dapat dinyatakan bahwa masingmasing indikator memiliki nilai cross loading > 0,70 terhadap variabel lain. Hal ini dilihat dari hasil korelasi konstruk (hubungan antar variabel) dari keselamatan dan kesehatan kerja (K3) X1.1=0,861 X1.2=0,843 $\mathrm{X} 1.3=0,714$, korelasi konstruk dari lingkungan kerja $\mathrm{X} 2.1=0,867, \mathrm{X} 2.2=0,773, \mathrm{X} 2.3=0,876$, korelasi konstruk dari produktivitas kerja lainnya $(\mathrm{Y} 1 \rightarrow \mathrm{Y} 1.1, \mathrm{Y} 1.2, \mathrm{Y} 1.3)$ dengan nilai $\mathrm{Y} 1.1=0,812, \mathrm{Y} 1.2=0,876, \mathrm{Y} 1.3=0,853$, sehingga variabel indikator bisa dikatakan valid karena korelasi indikator konstruknya lebih tinggi dari pada korelasi/hubungan indikator ke konstruk yang lain.

\section{c. Uji Reliabilitas}

Uji reliabilitas adalah merupakan tahap terakhir dalam permodelan outer model yang menjelaskan konsistensi dari semua hasil uji pengukuran yang sudah dilakukan ini. Hasil dari perhitungan data dengan uji reliabilitas dapat dilihat pada Tabel 7. 
Tabel 7. Nilai Cronbachs Alpha dan Composite Reliability

\begin{tabular}{|l|c|c|c|}
\hline \multicolumn{1}{|c|}{ Permodelan } & $\begin{array}{l}\text { Cronbac } \\
\text { hs Alpha }\end{array}$ & $\begin{array}{l}\text { Composite } \\
\text { Reliability }\end{array}$ & Keterangan \\
\hline $\begin{array}{l}\text { Keselamatan dan } \\
\text { Kesehatan Kerja } \\
\text { (X1) }\end{array}$ & 0.735 & 0.849 & Reliabel \\
\hline $\begin{array}{l}\text { Lingkungan Kerja } \\
\text { X2) }\end{array}$ & 0.793 & 0.878 & Reliabel \\
\hline $\begin{array}{l}\text { Produktifitas } \\
\text { Kerja(Y) }\end{array}$ & 0.805 & 0.844 & Reliabel \\
\hline
\end{tabular}

\section{Menghitung Pengukuran Inner Model}

Inner model adalah pengukuran yang dilakukan untuk mengetahui pengaruh antara variabel laten satu dengan variabel laten lainnya. Dalam uji ini mencari nilai $R$ square, kemudian untuk mengetahui nilai signifikan dari setiap pengaruh variabel maka akan dilakukan proses bootstrapping dengan nilai $R$ Square terdapat pada Tabel 8 ..

Tabel 8. Nilai $R$-Square

\begin{tabular}{|c|c|c|}
\hline Variabel & R-Square & $\begin{array}{c}\text { R-Square } \\
\text { Adjusted }\end{array}$ \\
\hline Produktifitas Kerja & 0.728 & 0.72 \\
\hline
\end{tabular}

Berdasarkan hasil pada tabel 8 diatas didapat nilai $R$ Square sebesar 0,728. Hal ini menunjukkan bahwa variabel keselamatan dan kesehatan kerja (X1), dan lingkungan kerja (X2) dapat berpengaruh terhadap produktifitas kerja (Y), dimana variabel keselamatan dan kesehatan kerja (X1), dan lingkungan kerja (X2) mampu menjelaskan produktivitas kerja (Y) sebesar $72,8 \%$.

Tabel 9. Hasil dari perhitungan smart pls

\begin{tabular}{|c|c|c|c|c|c|}
\hline $\begin{array}{c}\text { variabel laten } \\
\text { dengan } \\
\text { variabel laten }\end{array}$ & $\begin{array}{c}\text { Origin } \\
\text { al } \\
\text { Sample }\end{array}$ & $\begin{array}{c}\text { Sample } \\
\text { Mean } \\
(\boldsymbol{M})\end{array}$ & $\begin{array}{c}\text { Standard } \\
\text { Deviatio } \\
\boldsymbol{n} \\
(\text { STDEV })\end{array}$ & $\begin{array}{c}\boldsymbol{T} \text { - } \\
\text { Statisti } \\
\boldsymbol{c}\end{array}$ & $\begin{array}{c}\boldsymbol{P} \text { Va } \\
\text { lue }\end{array}$ \\
\hline $\begin{array}{c}\text { K3 (X1) } \rightarrow \\
\text { Produktifitas } \\
\text { kerja (Y) }\end{array}$ & 0.750 & 0.751 & 0.052 & 14.487 & 0 \\
\hline $\begin{array}{c}\text { Lingkungan } \\
\text { kerja (X2) } \rightarrow \\
\text { Produktifitas } \\
\text { kerja (Y) }\end{array}$ & 0.242 & 0.242 & 0.061 & 3.962 & 0 \\
\hline
\end{tabular}

Hasil dari pengujian hipotesis menggunakan permodelan outer model dan inner model didapatkan penjelasan pengaruh masing-masing variabel sebagai berikut:

Pada hasil pengujian yang didapat dari tabel 8 didapatkan nilai original sample keselamatan dan kesehatan kerja (X1) $\rightarrow$ Produktivitas kerja (Y) sebesar 0,750 (positif) sehingga menunjukkan bahwa hubungan antar variabel positif. Nilai untuk T-statistic sebesar 14,487, hal ini menjelaskan bahwa nilai $T$-statistic $>1,96$. Untuk hasil dari $P$-values didapatkan nilai sebesar 0,000, hal ini menjelaskan bahwa $P$-values signifikan karena $<0,05$. Dari semua hasil yang sudah didapat bisa dinyatakan bahwa keselamatan dan kesehatan kerja (X1) berpengaruh positif terhadap produktivitas kerja (Y). Sehingga dapat dijelaskan bahwa semakin tinggi penerapan keselamatan dan kesehatan kerja dalam proyek bisa berpengaruh dalam produktivitas kerja.

Menurut penelitian dari Christina dkk (2012) mengatakan bahwa semakin tinggi budaya keselamatan dan kesehatan kerja, maka semakin tinggi pula tingkat produktivitas kerja yang dihasilkan oleh suatu proyek konstruksi. Ini berarti bisa dijelaskan bahwa keselamatan dan kesehatan kerja memang sangat berpengaruh terhadap tingkat produktivitas kerja. Hal tersebut sesuai dengan hasil dari penelitian ini.

Pada hasil pengujian yang didapat dari tabel 8 didapat nilai original sample lingkungan kerja (X2) $\rightarrow$ produktivitas kerja (Y) sebesar 0,242 (positif) sehingga menunjukkan bahwa hubungan antar variabel positif. Nilai T-statistic sebesar 3,962, hal ini menjelaskan bahwa nilai $T$-statistic $>1,96$. Untuk hasil $P$-values sebesar 0,000, hal ini menjelaskan bahwa $P$-values signifikan karena $<0,05$. Dari semua hasil yang didapatkan bisa diartikan bahwa lingkungan kerja berpengaruh terhadap produktivitas kerja.

Menurut penelitian dari Hidayat dkk (2005) yang menyatakan bahwa faktor lingkungan kerja memiliki pengaruh yang cukup signifikan terhadap produktivitas kerja. Ini berarti bisa dijelaskan bahwa lingkungan kerja memang berpengaruh terhadap produktivitas kerja. Hal tersebut sesuai dengan hasil dari penelitian ini.Menurut Faris dan Harianto (2014) menyatakn bahwa lingkungan kerja tidak berpengaruh terhadap kecelakaan kerja yang berdampak akan produktivitas kerja dikarenakan lingkungan kerja yang kurang kondusif. Namun berbeda dengan penelitian ini yang menyatakan bahwa lingkunga kerja berpengaruh positif terhadap produktivitas kerja karena lingkungan kerja yang aman.

\section{UCAPAN TERIMAKASIH}

Terima kasih atas kerjasamanya dalam penelitian kepada pihak manajemen PT MULTIKON, PT PULAUINTAN, dan PT WIKA.

\section{KESIMPULAN DAN SARAN Kesimpulan}

Berdasarkan hasil penelitian dan pembahasan dapat diambil beberapa kesimpulan sebagai berikut:

1. Variabel keselamatan dan kesehatan kerja (X1) berpengaruh signifikan terhadap variabel produktivitas kerja (Y) karena nilai T-statistic 14,487 > 1,96. Semakin tinggi penerapan keselamatan dan kesehatan kerja dalam proyek maka semakin tinggi pula tingkat produktivitas kerja yang dihasilkan.

2. Variabel lingkungan kerja (X2) berpengaruh signifikan terhadap variabel produktivitas kerja (Y) karena nilai $T$-statistic 3,962 > 1,96. Semakin tinggi tingkat lingkungan kerja pada proyek maka semakin tinggi tingkat produktivitas kerja yang dihasilkan.

\section{Saran}

1. Disarankan bagi perusahan lebih memperhatikan dan menjalankan tentang prosedur keselamatan dan kesehatan kerja serta lingkungan kerja yang sudah ditetapkan harus diterapkan. Karena hal ini bisa meningkatkan produktivitas kerja di lokasi proyek. 
2. Disarankan kepada peneliti selanjutnya untuk meneliti variabel-variabel yang tidak diteliti dalam penelitian ini seperti fasilitas kerja, lingkungan disekitar proyek dan lain-lain yang berhubungan dengan kondisi dan jenis proyek yang akan dilakukan sebuah penelitian.

\section{DAFTAR PUSTAKA}

Christina, dkk. 2012. Pengaruh Budaya Keselamatan dan Kesehatan Kerja (K3) terhadap Kinerja Proyek Konstruksi. Jurnal Rekayasa Sipil. Vol 6 (1): 8395.

Faris, Iqbal Al dan Harianto, Feri. 2014. Pengaruh Perilaku Tenaga Kerja dan Lingkungan Kerja yang Dimoderasi Faktor Pengalaman Kerja dan Tingkat Pendidikan Terhadap Kecelakaan Kerja Konstruksi Di Surabaya. Skripsi tidak diterbitkan. Surabaya: Fakultas Teknik Sipil Institut Adhi Tama Surabaya.

Ghozali, Dkk. 2014. Partial Lest Squares Konsep Teknik Dan Aplikasi Menggunakan Program SmartPLS 3.0 Untuk Penelitian Empiris. Universitas Dipenogoro Semarang: Semarang.

Hidayat, dkk. 2014. Pengaruh Penerapan Keselamatan dan Kesehatan Kerja (K3) terhadap Kualitas Hasil Kerja dan Kenyamanan Pekerja pada Proyek Pembangunan Gedung Di Probolinggo. Jurnal Info Manajemen Proyek. Vol 5: 27-36.

Siswanto, Bayu Indra. 2015. Pengaruh Pelaksanaan Keselamatan dan Kesehatan Kerja Terhadap Produktivitas Kerja Karyawan Pada PT. Pembangunan Perumahan Tbk Cabang Kalimantan Di Balikpapan. Jurnal Administrasi Bisnis. Vol 3 (1): $68-82$.

Suardi, Rudi. 2007. Sistem Manajemen Keselamatan dan Kesehatan Kerja. Jakarta: PPM.

Wahyuni, dkk. 2018. Pengaruh Keselamatan dan Kesehatan Kerja (K3) terhadap Produktivitas Kerja Karyawan pada PT. Kutai Timber Indonesia. Jurnal Pendidikan Ekonomi. Vol 12 (1): 99-104. 
Jurnal Rekayasa Tenik Sipil Universitas Madura Vol. 5 No.1 Juni 2020 ISSN 2527-5542

Halaman Ini Sengaja Dikosongkan 